\title{
Investigation of a kindred with a new autosomal dominantly inherited variant type von Willebrand's disease (possible type IID)
}

\author{
FGH HILL, MS ENAYAT, AJ GEORGE \\ From the Departments of Haematology, The Children's and Queen Elizabeth Hospitals, Birmingham
}

SUMMARY A further type II variant of von Willebrand's disease has been identified in five family members who have the clinical symptoms of von Willebrand's disease. This variant is characterised by loss of high molecular weight VIIIR:AG multimers and the replacement of the normal triplet multimer configuration by a single dense band. In addition, variable minor bands are seen. These variants appear similar to those recently reported by Kinoshita et al and designated as type IID.

Patients with von Willebrand's disease have recently been reclassified and those with a quantitative defect of the FVIII/von Willebrand protein (VIIIR:AG/ vWF) have been designated as type $\mathrm{I}$ patients. These patients are characterised by the absence of the large multimers of VIIIR:AG/vWF as shown by crossed immunoelectrophoresis ${ }^{2}$ and sodium dodecyl sulphate (SDS) agarose gel electrophoresis. $^{34}$ This group can be further subdivided (types IIA and IIB) on the basis of differences in the multimeric structure abnormalities of VIIIR:AG/ $\mathrm{vWF}$ in plasma and platelets ${ }^{3}$ and by platelet agglutination studies with ristocetin. ${ }^{5}$ Recently, Ruggeri and Zimmerman have noted that in normal plasma and in plasma from patients with type II von Willebrand's disease each multimer consists of a triplet of bands. ${ }^{4}$ These authors also showed a difference in the triplet pattern in normal subjects and type IIA patients, while type I and IIB patients show the normal triplet configuration. ${ }^{5}$ Comparisons of type IIA patients have shown differences between patients in the concentration of protein in the constituent bands of the triplets. ${ }^{40} \mathrm{~A}$ further variant, type IIC, has been identified.' Unlike the autosomally dominant types IIA and IIB, type IIC is inherited in an autosomal recessive way and the plasma multimers consist of a repeating doublet instead of a triplet. Neither band of the doublet migrates on SDS agarose gel electrophoresis in a position similar to the bands present in normal, type

Accepted for publication 25 January 1985
IIA, or type IIB von Willebrand's disease plasmas. ${ }^{7}$ More recently, another recessively inherited variant has been described and in this patient the high molecular weight von Willebrand factor multimers are absent and the lower ones consist of a single band. ${ }^{8}$ The authors interpreted the family data as indicating that the abnormalities in the propositus arose from double heterozygosity for two different genes.

We report here a further variant in five family members. Discontinuous electrophoresis in SDS agarose acrylamide gel shows absent high molecular weight multimers and that the normal triplet configuration is absent and replaced by a single band that electrophoreses in the position of the central band of the normal triplet. The inheritance pattern is autosomal dominant. Abnormalities similar to those of our patients have recently been described in a mother and daughter and designated as type IID von Willebrand's disease."

\section{Patients and methods}

\section{PATIENTS}

The family tree is shown in Fig. 1. Twelve individuals in three generations have symptoms of abnormal haemostasis. Three of these have died, and two have refused to be tested; but six were tested, five of whom were abnormal. The clinical symptoms of the propositus (II19) and affected relatives are shown in Table 1. Seven other relatives were tested and found to be normal. 
IV

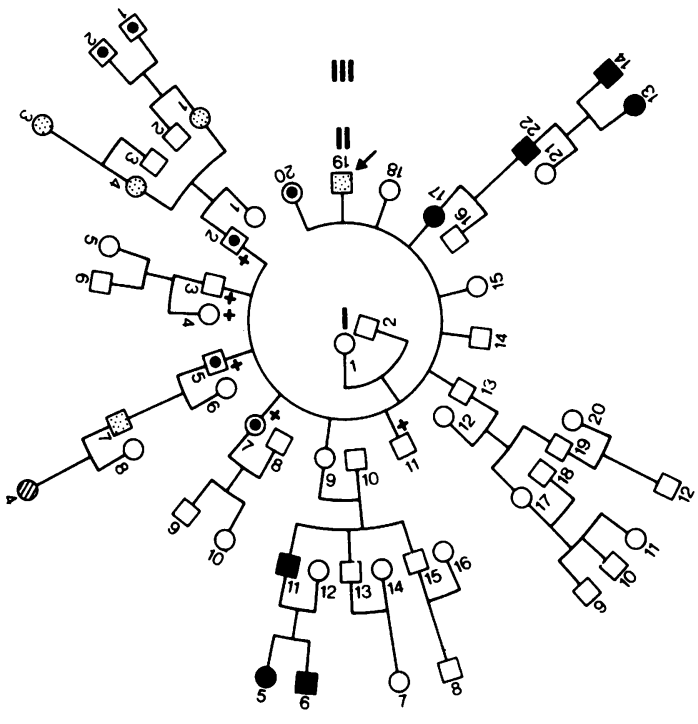

Females $\square$ Males

Clinical symptoms and abnormal on testing

OD Clinical symptoms but not tested

D Clinical symptoms but tested and normal

No symptoms. Tested and normal

^ Propositions

Fig. 1 Pedigree of affected family.

\section{METHODS}

\section{Platelets and plasma}

Venous blood was obtained from family members and normal men as controls. Nine parts of blood were added to one part of $0 \cdot 11 \mathrm{M}$ sodium citrate, and platelet rich plasma was prepared by centrifuging at $150 \mathrm{~g}$ for $10 \mathrm{~min}$ at room temperature and platelet poor plasma by centrifuging at $2700 \mathrm{~g}$ for 15 $\min$ at $4^{\circ} \mathrm{C}$. The standard for the factor VIII procoagulant activity (VIII:C) was a $100 \%$ reference plasma (Immuno Diagnostics Ltd), which is compared regularly with the NIBS FVIII British Standard. The standard for the factor VIII related antigen (VIIIR:AG) was an Immuno Diagnostics Ltd standard (value $1 \cdot 15 \mathrm{u} / \mathrm{ml}$ ) and a pool of 30 normal men (value $1.0 \mathrm{u} / \mathrm{ml}$ ). The latter was also used as the standard for the von Willebrand factor (VIIIR:WF) assay. Platelets were washed with edetic acid Tris buffer and concentrated by centrifuging on to $34 \% \mathrm{wt} / \mathrm{vol}$ bovine albumin. ${ }^{10}$ Twice washed fresh platelets were used in the VIIIR:WF assay. Six times washed platelets were frozen and thawed six times to provide platelet lysates for multimeric analysis of platelet VIIIR:AG.

Ristocetin was supplied by Lundbeck A/S Denmark, and agarose was supplied by BDH Poole, Dorset. Rabbit antihuman FVIII serum was supplied by Behringwerke and used for the Laurell technique of quantitative immunoelectrophoresis and in the crossed immunoelectrophoresis. Another antiserum (Dako rabbit antihuman VIII immunoglobulin labelled with iodine-125) was used for identifying the multimers of VIIIR:AG.

Bleeding time was measured using a Simplate device (General Diagnostics).

VIII:C was measured using a two stage assay as described elsewhere" employing a lyophilised incubation mixture.

VIIIR:AG was measured by a modified Laurell technique. ${ }^{12}$

VIIIR:AG electrophoretic mobility was determined by crossed immunoelectrophoresis as described previously. ${ }^{13}$

VIIIR:WF was measured by a modification of the method described by Weiss et al, ${ }^{14}$ as described previously. ${ }^{15}$

Platelet aggregation studies

Quantitative platelet aggregation was performed on

Table 1 Bleeding problems of symptomatic family members

\begin{tabular}{|c|c|c|c|c|c|c|c|c|}
\hline Initials & $\begin{array}{l}\text { Generation } \\
\text { no }\end{array}$ & Sex & $\begin{array}{l}\text { Easy } \\
\text { bruising }\end{array}$ & $\begin{array}{l}\text { Prolonged } \\
\text { bleeding from cuts }\end{array}$ & Epistaxes & $\begin{array}{l}\text { Bleeding after } \\
\text { dental extractions }\end{array}$ & $\begin{array}{l}\text { Gastrointestinal } \\
\text { tract bleeding }\end{array}$ & Menorrhagia \\
\hline $\begin{array}{l}\text { TL } \\
\text { NW } \\
\text { MB } \\
\text { TB } \\
\text { AL } \\
\text { AL Jr } \\
\text { EL } \\
\text { LL }\end{array}$ & $\begin{array}{l}\text { II2† } \\
\text { III 1* } \\
\text { III4* } \\
\text { IV3 } \\
\text { II5† } \\
\text { III7 } \\
\text { II7† } \\
\text { II19 }\end{array}$ & $\begin{array}{l}\mathbf{M} \\
\mathbf{F} \\
\mathbf{F} \\
\mathbf{F} \\
\mathbf{M} \\
\mathbf{M} \\
\mathbf{F} \\
\mathbf{M}\end{array}$ & $\begin{array}{l}++ \\
++ \\
++ \\
++ \\
+ \\
+ \\
+ \\
+\end{array}$ & $\begin{array}{l}\text { Not known } \\
\text { No cuts } \\
+ \\
+ \\
\text { Not known } \\
\text { Not known } \\
\text { Not known } \\
\text { Not known }\end{array}$ & $\begin{array}{l}+ \\
\text { None } \\
\text { None } \\
+ \\
+ \\
+ \\
+ \\
\text { None }\end{array}$ & $\begin{array}{l}++ \\
+ \\
+ \\
+ \\
\text { No } \\
\text { No } \\
+ \\
++\end{array}$ & $\begin{array}{l}\text { None } \\
\text { None } \\
\text { None } \\
\text { None } \\
++ \\
\text { None } \\
++ \\
++\end{array}$ & $\begin{array}{l}- \\
++ \\
++ \\
++ \\
- \\
- \\
\text { Not known } \\
-\end{array}$ \\
\hline
\end{tabular}

Only electively performed operations have been covered with cryoprecipitate and no abnormal bleeding occurred.

*Postpartum haemorrhage.

†Died. 
platelet rich plasma with a platelet count of $300 \times$ $10^{4} / 1$ using a dual channel aggregometer (Malin Electronics Ltd, Ayr, Scotland). All were tested with ADP (BDH), collagen (Hormon-Chemie, Munich), and ristocetin (at final concentrations of $1 \mathrm{mg} / \mathrm{ml}, 1.25 \mathrm{mg} / \mathrm{ml}$, and $1.5 \mathrm{mg} / \mathrm{ml}$ ). Aggregation patterns were compared with those of platelet rich plasma from a normal control tested under identical conditions.

Multimeric analysis of VIIIR:AG was done by a modification of the method of Ruggeri and Zimmerman $^{4}$ as described elsewhere. ${ }^{16}$

\section{Results}

The pedigree is shown in Fig. 1. Tables 1 and 2 show the clinical symptoms, and the bleeding times and factor VIII parameters respectively. Affected individuals have been identified in three generations with male to female, male to male, and female to female transmission. The abnormality thus appears to be inherited in an autosomal dominant way. The only abnormality in platelet aggregation was with ristocetin. Aggregation was absent with ristocetin at final concentrations of 1 and $1.25 \mathrm{mg} / \mathrm{ml}$ and reduced with a concentration of $1.5 \mathrm{mg} / \mathrm{ml}$.

Crossed immunoelectrophoresis showed a precipitin arc pattern for patient LL different from that seen in normal plasma or that of a type IIA patient (HW, Fig. 2). For patient LL the VIIIR:AG precipitin arc showed a slight increase in anodal migration with the presence of the more cathodal component (missing in HW). VIIIR:AG multimeric analysis patterns for the five affected family members (Fig. 3) were abnormal in that the highest molecular weight multimers were absent and the normal triplet pattern seen clearly in normal plasma was not seen. These patients had a dense band which electrophoresed in an identical position to the central band in the normal and IIA triplet, but the other bands (a and $b$ ) that constitute the triplet were absent. These patients did, however, have a series of much fainter bands present, one between bands 3 and 2, two between bands 2 and 1 , and three below band 1 . The degree of deletion of multimer bands varied between patients: LL and AL had nine bands; the sis- ters NW and MB had seven clear and a faint eighth band; while TB, MB's daughter, had only six bands present. The degree of deletion did not correlate with clinical severity. The multimeter pattern of the platelet lysates was identical to the plasma pattern.

Two patients, LL and MB, were given cryoprecipitate infusions before major surgery. In LL the VIIIR:WF was $1.8 \mu / \mathrm{ml}$ after transfusion and the bleeding time corrected from 17 to $5 \mathrm{~min}$. Plasma was taken immediately before and half an hour after the completion of the cryoprecipitate infusion and the VIIIR:AG multimer composition was determined. Crossed immunoelectrophoresis showed a striking change in the character of the precipitin arc (Fig. 4). A pre-peak was present in the pre- and postinfusion samples, but after the cryoprecipitate infusion two other peaks were seen. The more anodal peak had the same degree of migration as normal VIIIR:AG and the second peak that of the patient's preinfusion sample. Multimeric analysis (Fig. 5) patterns showed that before and after cryoprecipitate infusion the abnormal bands were clearly seen, but in the post-transfusion samples high molecular weight VIIIR:AG multimers and some additional bands in association with the lower molecular weight bands were seen. Normal triplet patterns. ${ }^{3}$ Those with type IIA have abnormal triplet patterns, ${ }^{40}$ but the recently lower multimers of the patient are present in higher concentration than the transfused normal ones with consequent masking of the normal multimers.

\section{Discussion}

Studying variant von Willebrand's disease patients using SDS agarose electrophoresis has indicated an increasing complexity of the molecular variants. The higher multimers are absent in the plasma of all type II patients, but those with type IIB have normal triplet patterns. ${ }^{3}$ Those with type IIA have abnormal triplet patterns, ${ }^{46}$ but the recently described type IIC has a doublet instead of a triplet pattern for the lower multimers.' In type IIC patients' plasma neither band of the doublet migrates in a position similar to the bands in the triplet of normal, IIA, or IIB plasmas. In a compari-

Table 2 Haemostatic values for affected individuals

\begin{tabular}{|c|c|c|c|c|c|}
\hline Initials & Generation no & $\begin{array}{l}\text { Bleeding time } \\
\text { (Ivy) (min) }\end{array}$ & $\begin{array}{l}\text { VIII:C } \\
(u / m l)\end{array}$ & $\begin{array}{l}\text { VIIIR:AG } \\
(u / m l)\end{array}$ & $\begin{array}{l}\text { VIIIR:WF } \\
(u / m l)\end{array}$ \\
\hline $\begin{array}{l}\text { NW } \\
\text { MB } \\
\text { TB } \\
\text { AL Jr } \\
\text { LL }\end{array}$ & $\begin{array}{l}\text { III1 } \\
\text { III4 } \\
\text { IV3 } \\
\text { III7 } \\
\text { II19 }\end{array}$ & $\begin{array}{r}18 \\
17 \\
19 \\
9 \\
17\end{array}$ & $\begin{array}{l}0.69 \\
0.64 \\
0.58 \\
0.68 \\
1.42\end{array}$ & $\begin{array}{l}0.90 \\
1.16 \\
0.89 \\
0.72 \\
2.02\end{array}$ & $\begin{array}{l}0.16 \\
0.33 \\
0.30 \\
0.10 \\
0.25\end{array}$ \\
\hline
\end{tabular}




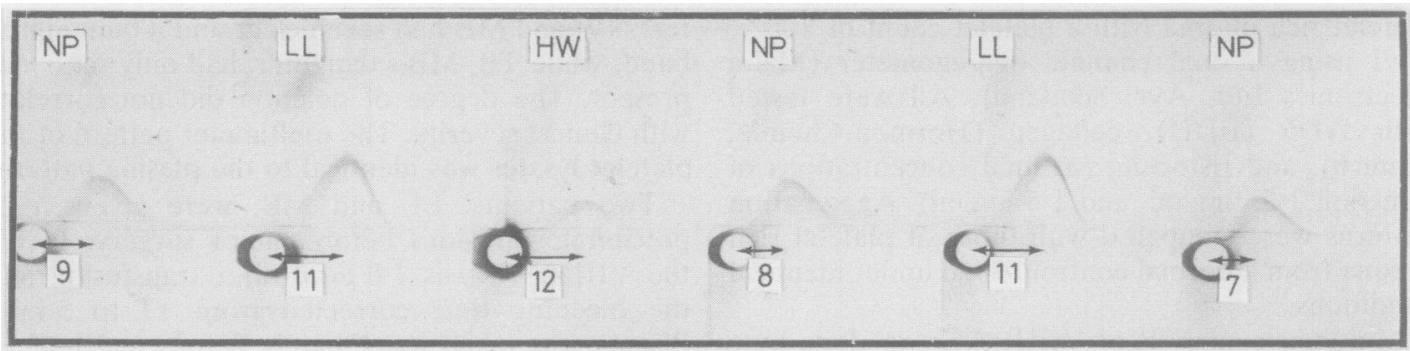

Fig. 2 Crossed immunoelectrophoresis of plasma VIIIR:AG comparing propositus ( $L L)$, with normal subject (NP), and IIA variant $(H W)$.

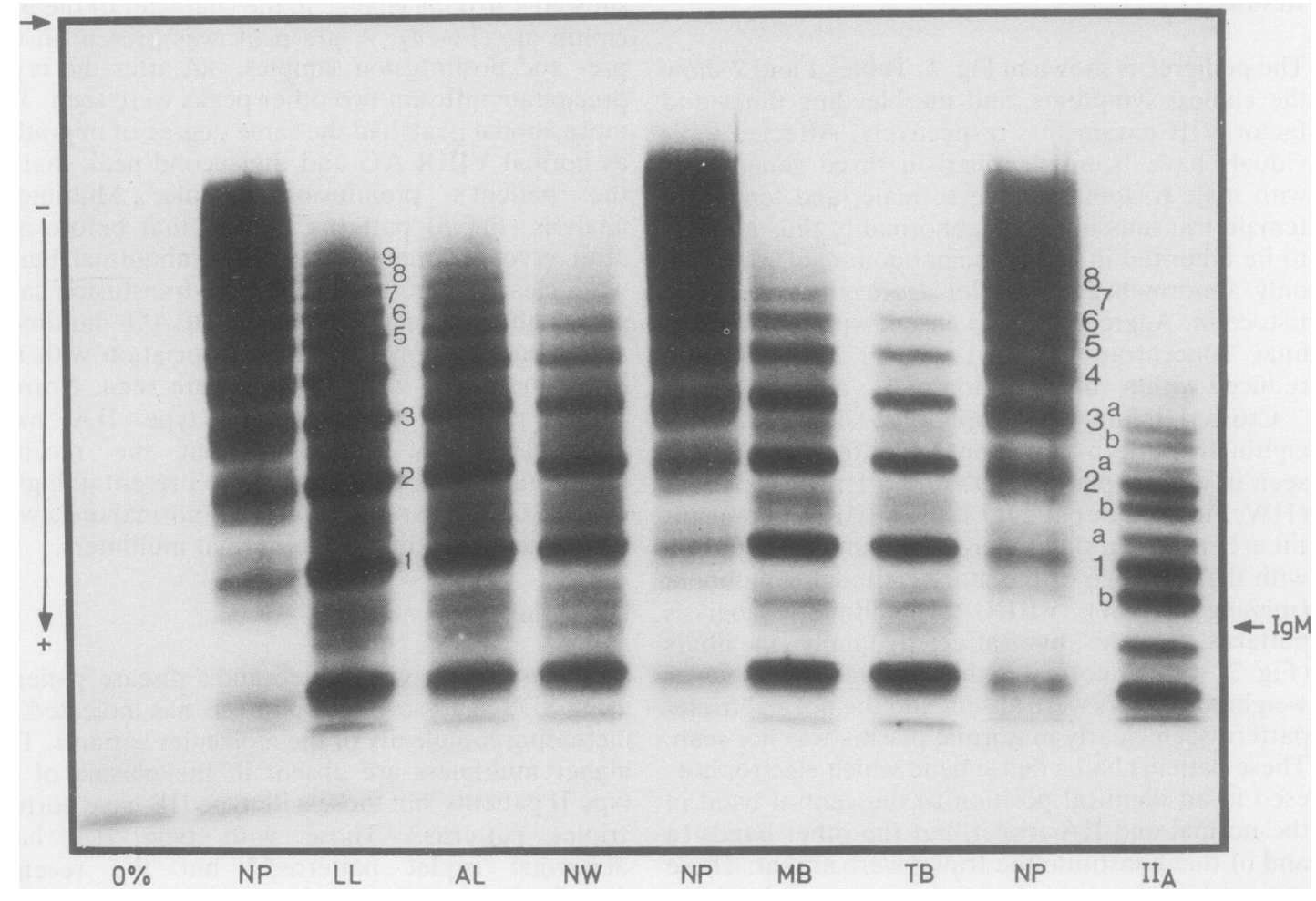

Fig. 3 Plasma VIII:AG multimeric analysis patterns of five affected family members $\left(L L\left(I I_{19}\right), A L\left(I I I_{7}\right), N W\left(I I I_{1}\right)\right.$, $M B\left(I I I_{4}\right)$, and $\left.T B\left(V_{3}\right)\right)$; normal subject (NP); and a IIA variant (IIA).

Son by Mannucci et $\mathbf{l}^{8}$ the type IIC variant and the patient reported by Armitage and Rizza ${ }^{17}$ appear to have similar multimer patterns. A double heterozygous inheritance pattern has been shown for Armitage and Rizza's patient, while the type IIC variant has an autosomal recessive inheritance. The new variant reported recently by Mannucci et $\mathrm{al}^{8}$ has' a double heterozygous inheritance pattern and multimeric analysis shows the multimers to consist of a single band.
In the family reported here the inheritance pattern is autosomal dominant. The multimer pattern superficially appears most similar to that seen in the patient of Mannucci $e t a l$, but there are differences in that multimeric analysis of our patients' plasma shows faint bands between the lower multimers, but these bands do not form a regular pattern. Another difference on multimeric analysis between our patients and Mannucci's patient is that the lowest multimer, although increased in concentration com- 


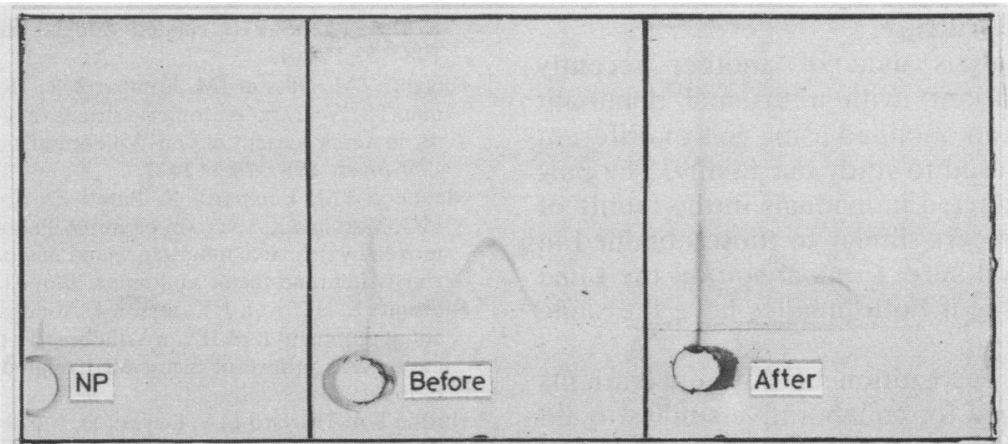

Fig. 4 Crossed immunoelectrophoretic plasma VIIIR:AG precipitin arcs for normal subject $(N P)$ and patient $L L\left(I_{19}\right)$ before and half an hour after a cryoprecipitate infusion.

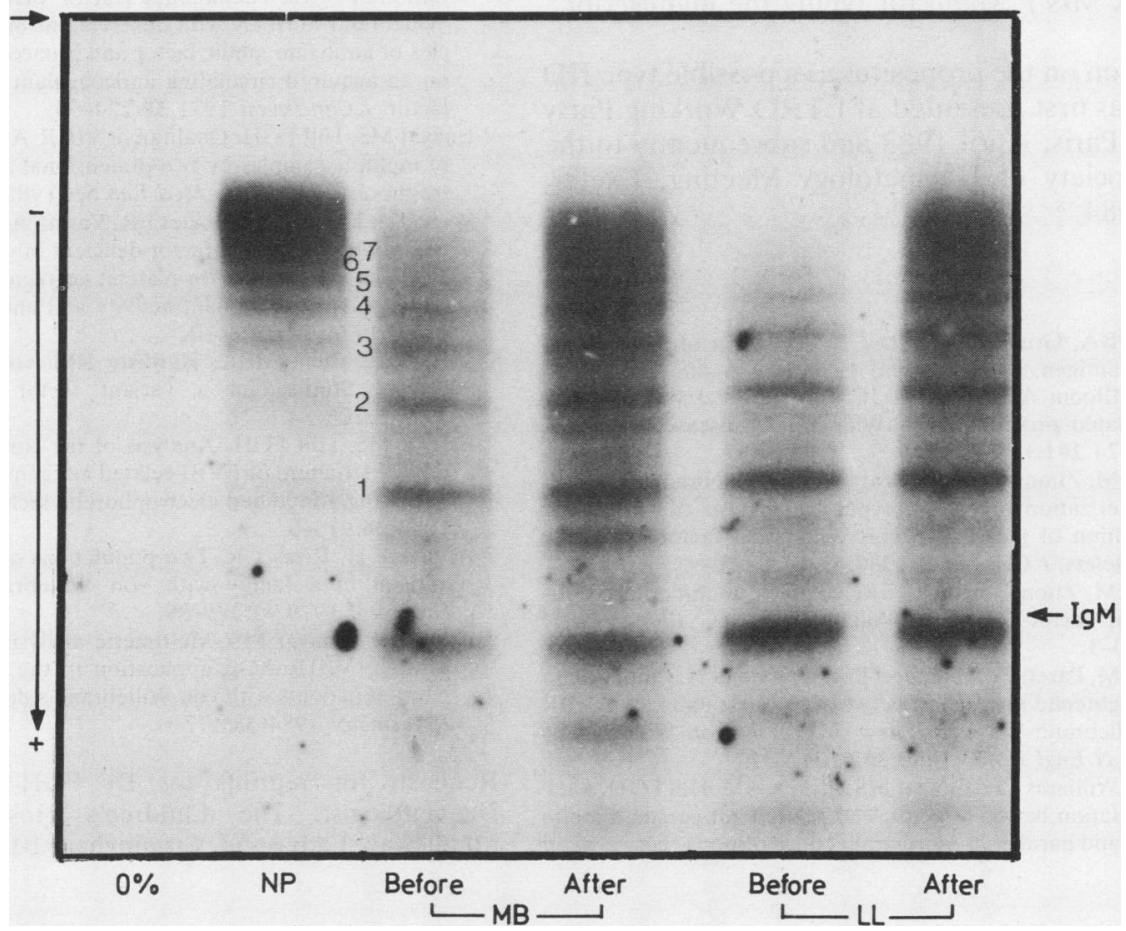

Fig. 5 Plasma VIIIR:AG multimeric analysis patterns in a severe $(0 \%)$ case of classical von Willebrand's disease, a normal subject (NP), and in two affected family members (MB and $L L$ ) before and after a cryoprecipitate transfusion. Note the appearance of the high molecular weight multimers but the persistence of the patients' abnormal multimer pattern.

pared with that of normal plasma, is not any more concentrated than band 2, whereas in Mannucci's patient and the type IIC patient the concentration of the lowest multimer is greatly increased compared with that patient's other multimers and those of normal plasma.
It appears, therefore, that the family reported here has a further distinct genetic variant of VIIIR:AG resulting in a von Willebrand's disease type haemostatic disorder. This new variant is characterised by autosomal dominant inheritance and an abnormal VIIIR:AG multimer pattern includ- 
ing absent triplet structure.

Multimeric analysis data of another recently described new variant" with autosomal dominant inheritance has been obtained using gels of different porosity to those used to study our family. The pattern in the two affected individuals in the family of Kinoshita et al appears similar to those obtained in the family reported here. Comparison on the same gel is needed to see if both families have the same defect.

The increasing recognition of different variants emphasises the need for collaborative studies to aid reclassifying the von Willebrand's variants and to increase our understanding of the function and structure of VIIIR:AG.

We acknowledge the support of Action Research and thank Mrs P Mann for typing the manuscript.

Information on the propositus as a possible type IID variant was first presented at ETRO Working Party Meeting, Paris, April 1983 and subsequently to the British Society of Haematology Meeting, Exeter, March 1984. ${ }^{18}$

\section{References}

' Kernoff PBA, Gruson R, Rizza CR. A variant of factor VIIIrelated antigen. $\mathrm{Br} J$ Haematol 1974;26:435-40.

${ }^{2}$ Peak IR, Bloom AL, Giddings JC. Inherited variants of factor VIII-related protein in von Willebrand's disease. $N$ Engl $J$ Med 1974;291:113-7.

${ }^{3}$ Ruggeri ZM, Zimmerman TS. Variant von Willebrand's disease: Characterization of two subtypes by analysis of multimeric composition of factor VIII/von Willebrand factor in plasma and platelets. J Clin Invest 1980;65:1318-25.

${ }^{4}$ Ruggeri ZM, Zimmerman TS. The complex multimeric composition of factor VIII/von Willebrand factor. Blood 1981; 57:1140-3.

s Ruggeri ZM, Pareti FI, Mannucci PM, Ciavarella N, Zimmerman TS. Heightened interaction between platelets and factor VIII/ von Willebrand factor in a new subtype of von Willebrand's disease. $N$ Engl J Med 1980;302:1047-51.

- Short PE, Williams CE, Enayat MS, Picken AM, Hill FGH. Lack of correlation between factor VIII related antigen multimeric pattern and parallel or non-parallel dose response curves in an
ELISA factor VIII related antigen assay. J Clin Pathol 1984;37:194-9.

' Ruggeri ZM, Nilsson IM, Lombardi R, Holmberg L, Zimmerman TS. Aberrant multimeric structure of von Willebrand factor in a new variant of von Willebrand's disease (Type IIC). $J$ Clin Invest 1982; 70:1124-7.

${ }^{8}$ Mannucci PM, Lombardi R, Pareti FI, Solinas S, Mazzucconi MG, Mariani G. A variant of von Willebrand's disease characterized by recessive inheritance and missing triplet structure of von Willebrand factor multimers. Blood 1983;62:1000-5.

' Kinoshita S, Harrison J, Lazerson J, Abildgaard CF. A new variant of dominant type II von Willebrand's disease with aberrant multimeric pattern of factor VIII related antigen (type IID). Blood 1984;63:1369-71.

${ }^{10}$ Hutton RA, Howard MA, Deykin D, Hardisty RM. Methods for the separation of platelets from plasma. A comparison of functional and morphological integrity. Thrombos Diathes Haemorrh 1974;31:119-32.

" Pool JG, Robinson J. Assay of plasma antihaemophilic globulin (AHG). Br J Haematol 1959;5:17-23.

${ }^{12}$ Zimmerman TS, Ratnoff OD, Powell AE. Immunologic differentiation of classic haemophilia (factor VIII deficiency) and von Willebrand's disease with observations on combined deficiencies of antihaemophilic factor and proaccelerin (factor $V$ ) and on an acquired circulating anticoagulant against haemophilic factor. J Clin Invest 1971;50:224-54.

${ }^{13}$ Enayat MS, Hill FGH. Qualitative VIIIR: AG function screening of multiple samples by two dimensional crossed immunoelectrophoresis technique. Med Lab Sci 1982;39:357-62.

${ }^{14}$ Weiss HJ, Hoyer LW, Rickles FR, Varma A, Rogers J. Quantitative assay of a plasma factor deficient in von Willebrand's disease that is necessary for platelet aggregation. Relationship to factor VIII procoagulant activity and antigen content. J Clin Invest 1973;52:2708-10.

is Hill FGH, Chan MCK, Hardisty RM. von Willebrand's syndrome. Studies on a variant factor VIII. Haemostasis 1976;5:276-84.

16 Enayat MS, Hill FGH. Analysis of the complexity of the multimeric structure of FVIII related antigen/von Willebrand protein using a modified electrophoretic technique. J Clin Patho 1983;36:915-9.

17 Armitage H, Rizza CR. Two populations of factor VIII-related antigen in a family with von Willebrand's disease. $\mathrm{Br} J$ Haematol 1979;41:279-89.

${ }^{18}$ Hill FGH, Enayat MS. Multimeric analysis of von Willebrand protein (VIIIR:AG); application to the diagnosis and treatment of patients with von Willebrand's disease. (Abstract). $\mathrm{Br}$ J Haematol 1984;58:177.

Requests for reprints to: Dr FGH Hill, Consultant Haematologist, The Children's Hospital, Ladywood Middleway, Ladywood, Birmingham B16 8ET, England. 